INTERNATIONAL JOURNAL OF SCIENTIFIC RESEARCH

\title{
STUDY ON LEVELS OF SERUM IRON AND SERUM FERRITIN IN ADOLESCENT DEPRESSION IN A TERTIARY CARE HOSPITAL
}

\section{Clinical Research}

\section{Dr Madhurima}

Bora

\author{
Associate Professor Deptt. of Biochemistry GMCH,
}

\begin{tabular}{ll}
\hline Dr Sherin Gogoi* & Assistant Professor Deptt. of Biochemistry GMCH. *Corresponding Author \\
\hline Dr Puja Bora & PGT student Deptt. of Psychiatry, GMCH \\
\hline
\end{tabular}

ABSTRACT

INTRODUCTION: A notable feature of patients suffering from mental disorders is the severity of deficiency in the nutrients in diets especially essential vitamins, minerals and omega-3 fatty acids. Iron is a vital nutrient that plays a role in every cell of the body, the deficiency of which will cause depression besides lack of energy, dizziness, light headedness and pale skin. AIM: The study is aimed to estimate serum iron and Ferritin in adolescent depression cases and to evaluate their role in adolescent depression.METHOD MATERIAL: Patients in the age group of 13 - 19 years, suffering from depression, and attending Psychiatry OPD of Gauhati Medical College are taken as cases. Controls are healthy individuals in the same age group. Samples are collected and serum iron and ferritin are estimated and compared between the two groups. Data are analyzed with the help of Minitab-19 and in MS-excel. RESULTS: Both serum iron and ferritin are decreased significantly in group containing adolescent with depression. Both are highly significant $\mathrm{P}<0.001$ with 't' values 14.42 and 13.11 respectively. CONCLUSION: This Study gives us an idea that while investigating a case of adolescent depression, emphasis must be given to the nutritive status (iron and ferritin) of the individual also.

\section{KEYWORDS}

\section{Depression, Adolescent, Iron, Ferritin}

\section{INTRODUCTION:}

People easily think about the relation of nutritional deficiency with physical illness but forget that nutrition has an important role in the onset and duration of depression. The most common mental disorder that are currently prevalent in numerous countries are depression, bipolar disorders, schizophrenia and obsessive compulsive disorders (OCD) [1] Depression is defined as a cluster of specific symptoms with associated impairment affecting 7.4\% of adolescent (10- 14 years) globally.[2] The clinical and diagnostic features of the disorder are broadly similar in adolescents and adults.[3,4] But American diagnostic and statistical manual of mental disorder IV (DSM IV) shows one exception for children and adolescent whereby irritability rather than depressed mood is allowed as a core diagnostic symptom. [5] The prevalence of depression in children is low $(<1 \%$ in most studies) [6] with no sex difference and then rises substantially throughout adolescence.[7] The dietary intake of general population in many Asian and American countries reflects that they are often deficient in many nutrients especially essential vitamins, minerals and omega-3 fatty acids.[8] A notable feature of the diets of patients suffering from mental disorders is the severity of deficiency in these nutrients. Iron is a vital nutrient that plays a role in every cell of the body and it is an important component of heme of hemoglobin, the deficiency will cause iron deficiency anemia. Besides the common symptoms of iron deficiency anemia like lack of energy, dizziness, light headedness and pale skin, it may also contribute to depression because of its relationship with dopamine, one of the neurotransmitters in the brain. Iron is required for the production of dopamine in the brain. [9] Iron is required for proper myelination of the spinal cord and brain white matter of cerebellar folds and it is a cofactor for a number of enzymes such as tryptophan hydroxylase (serotonin) and tyrosine hydroxylase ( for norepinephrine and dopamine).[10] Our bodies use tyrosine from protein rich foods to produce dopamine but this only happens in the presence of iron.[11] Both phenylalanine hydroxylase and tyrosine hydroxylase require iron as cofactor along with other cofactors to form dopamine, epinephrine and norepinephrine. This is depicted in figure 1. A lack of dopamine can lead to depression, anxiety and even movement disorders like restless leg syndrome. The oligodendrocytes are responsible for production of myelin sheets as they comprise iron in brain cells. But with deficiency of iron, oligodendrocytes will be immature and this will cause delay in motor maturation and perhaps behavioral alterations.

Figure 1:

Synthesis of Catecholamines
(Phenylalanine hydroxylase enzyme)
Cofactors - Iron, niacin, and tetrahydrobiopterin (BH4)
(Tyrosine hydroxylase enzyme)
Cofactors - Iron, niacin, folic acid, tetrahydrobiopterin (BH4)
(Aromatic L-amino acid decarboxylase - AKA Dopa decarboxylase enzyme)
Cofactor - P5P, which is the active form of B6
Nopamine
(Dopamine beta Hydroxylase enzyme)
Cofactors - Copper and vitamin C
(COMT and MAO Enzymes are Needed for Breakdown of Dopamine, Norepinephrine
and Epinephrine)
(Phenylethanolamine N-methyltransferase enzyme)
Cofactors - SAMe and magnesium


Iron has different roles in brain metabolism like incorporation into enzymes of oxidation-reduction or electron transport, synthesis and packaging of neurotransmitters and uptake and degradation of the neurotransmitters into iron containing proteins that may directly or indirectly alter brain function through peroxide reduction, amino acid metabolism, fat desaturation and altering membrane function. [12]

Ferritin is a universal intracellular protein that stores iron and releases it in a controlled fashion. In humans, it acts as a buffer against iron deficiency and iron overload.[13] Ferritin is found in most tissues as a cytosolic protein but small amounts are secreted into the serum where it functions as an iron carrier. Plasma ferritin is also a marker of the total amount of iron stored in the body. Ferritin is a globular protein complex consisting of 24 protein subunits forming a nanocage with multiple metal-protein. In an ordinary diet, less than $10 \%$ of dietary iron is absorbed. Iron is present in food as ferric hydroxide, $\mathrm{Fe}(\mathrm{OH})_{3}$ or ferric organic compounds. $\mathrm{HCl}$ frees ferric $\left(\mathrm{Fe}^{3+}\right)$ iron that is reduced into ferrous form $\left(\mathrm{Fe}^{2+}\right)$ by dietary reducing substances such as Lascorbic acid, cysteine and glutathione. Ferrous form is the only form transferred across cell membrane since transporters are valence sensitive. The divalent metal transporter on apical intestinal epithelial cell transports $\mathrm{Fe}^{2+}$ iron, which is then oxidized to $\mathrm{Fe}^{3+}$ to bind apoferritin (an iron-binding protein synthesized in the intestinal mucosa and other iron requiring cells) to form ferritin. Ferritin liberates ferric ions that are converted into ferrous form by the multicopper ferroxidase, ceruloplasmin, while apoferritin is regenerated. Ferrous iron is then transported into the blood through the iron transporter on the basolateral membrane of enterocytes. In the plasma it is rapidly oxidized to $\mathrm{Fe}^{3+}$ (by ceruloplasmin) and combines with iron binding protein transferrin. Each molecule of transferrin carry two atoms of iron in ferric state. Most of the iron is taken up by the bone marrow to synthesize hemoglobin. Iron from ferritin can be released into plasma and carried by transferrin to be utilized by bone marrow and other tissues. The patients affected by iron deficiency anemia show many mood and behavioural signs and symptoms similar to the depressed individuals. Of note, many of these signs and symptoms occur in the initial stage of iron deficiency (decrease level of serum ferritin) before the establishment of frank anemia. [14]

\section{AIMS AND OBJECTIVES:}

\section{The study aims:}

1) To estimate the levels of serum iron and serum ferritin in adolescent depression cases and in normal healthy adolescents.

2) To compare the levels of serum iron and serum ferritin in cases and control groups

\section{STUDY DESIGN:}

The study is a hospital based case-control study conducted in the central clinical laboratory (Biochemistry) department in collaboration with Psychiatry department, Gauhati Medical College, Guwahati-5

\section{STUDY POPULATION:}

Patients in the age group of $10-19$ years (adolescent age according to WHO) suffering from depression, attending Psychiatry OPD of Gauhati Medical College. Controls are healthy individuals in the same age group.

\section{SAMPLE SIZE :}

90 samples are taken out of which 45 are cases and 45 are control.

\section{STUDY DURATION: 1(one) year}

\section{INCLUSION CRITERIA:}

- Patients suffering from depression in the age group 10 - 19yrs

- No familial history of depression

- No intake of antidepressants

\section{EXCLUSION CRITERIA:}

- Familial history of depression

- Intake of antidepressants

- Intake of iron supplements

- Any acute infections

\section{METHODS:}

Procedure: With all aseptic and antiseptic measures $5 \mathrm{ml}$ whole blood is to be drawn from the median cubital vein and centrifuged in a centrifuge machine for 5 minutes at the rate of $3000 \mathrm{rpm}$. Then the serum is taken for analysis of serum Ferritin and serum Iron. Serum Ferritin and serum iron is estimated by micro slide using photometry, both in vitreos 5600

\section{Statistical analysis:}

The results were expressed as mean \pm standard deviation. The data analysis is carried out using student "t" test. [15] Comparison of parameters between normal healthy adolescents (control) and depressed adolescents are done with student ' $t$ ' test (paired " $t$ " test). A ' $\mathrm{P}$ ' value $<0.05, \mathrm{P}<0.01$ and $\mathrm{P}<0.001$ are considered statistically significant, Data are analyzed with the help of Minitab-19 and in MSexcel.

\section{RESULTS:}

In this study, 90 adolescents were taken out of which 45 were diagnosed case of adolescent depression (unipolar). The control group consists of 45 healthy adolescents. Results of the study are given in Table 1, 2, 3 and 4. In Table 1, mean values \pm SD of serum iron of cases ie group of adolescent having depression shows a decreasing trend when compared to control group of normal healthy adolescents. It is depicted in the figure 7 . It is highly significant $\mathrm{P}<0.001$ with a" $t$ " value of (14.42). In Table 1 mean values $\pm \mathrm{SD}$ of serum Ferritin is decreased in group of adolescents having depression when compared to normal adolescents. It is also significant $\mathrm{P}<0.001$ with a 't' value of (13.11) The decrease of serum ferritin is shown in figure 6 . The sex ratios of cases of adolescents with depression are in Table $3 \& 4$ and figure $8 \& 9$ with a rise is observed among females.

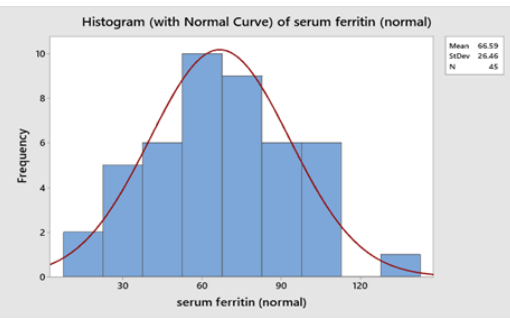

Figure 2:

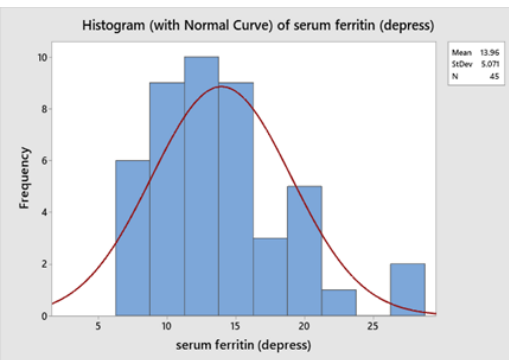

Figure 3:

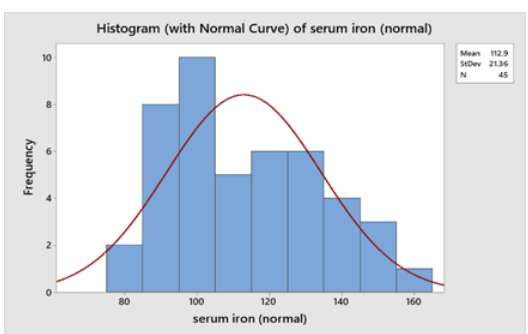

Figure 4:

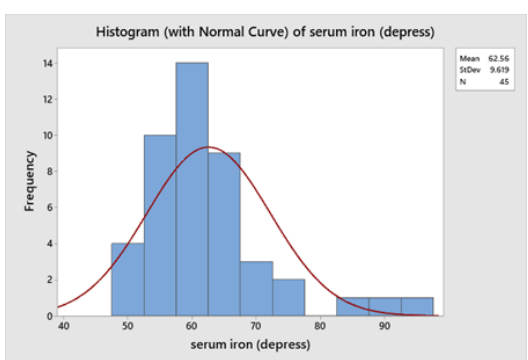

Figure 5: 


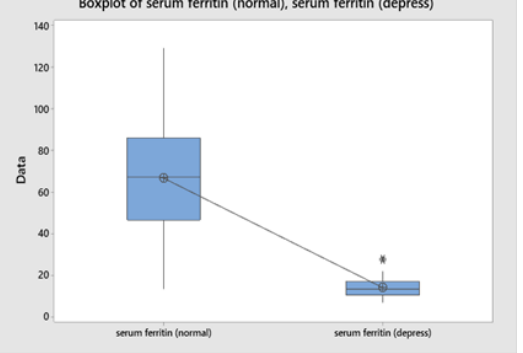

Figure 6:

Figure 7:

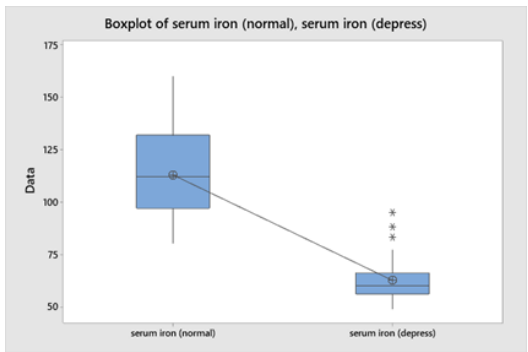

Table 1- Statistical analysis of serum Iron and Ferritin in normal adolescents and adolescents:

\begin{tabular}{|l|l|l|l|l|}
\hline & \multicolumn{3}{|l|}{ serum Ferritin } & \multicolumn{2}{l|}{ serum Iron } \\
\hline & Normal & Depression & normal & depression \\
\hline mean+/-SD & $66.6 \pm 26.46$ & $13.9 \pm 5.07$ & $112.9 \pm 21.4$ & $62.56 \pm 9.6$ \\
\hline SE & 3.9 & 0.76 & 3.2 & 1.4 \\
\hline min-max & $13.10-129$ & $6.9-28$ & $80-160$ & $49-95$ \\
\hline variance & 700.17 & 25.72 & 456 & 92.53 \\
\hline $\begin{array}{l}\text { Coefficient } \\
\text { variance }\end{array}$ & 39.73 & 36.34 & 18.92 & 15.38 \\
\hline
\end{tabular}

Table 2-P and $t$ values when compared with normal adolescents:

\begin{tabular}{|l|l|l|l|}
\hline Parameter & & Serum Iron & Serum Ferritin \\
\hline \multirow{2}{*}{$\begin{array}{c}\text { Adolescents } \\
\text { with depression }\end{array}$} & P value & $<0.001$ & $<0.001$ \\
\cline { 2 - 4 } & T value & 14.42 & 13.11 \\
\hline
\end{tabular}

Table 3: Sex distribution among healthy adolescents.

\begin{tabular}{|l|l|l|}
\hline Total cases & male & Female \\
\hline 45 & $20(45.5 \%)$ & $25(54.5 \%)$ \\
\hline
\end{tabular}

Table 4: Sex distribution among adolescents with depression:

\begin{tabular}{|l|l|l|}
\hline Total cases & Males & Females \\
\hline 45 & $17(32.78 \%)$ & $28(67.22 \%)$ \\
\hline
\end{tabular}

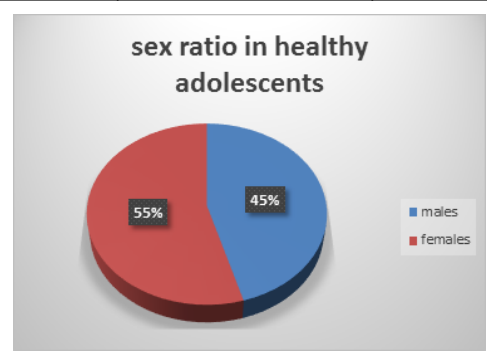

Figure 8:

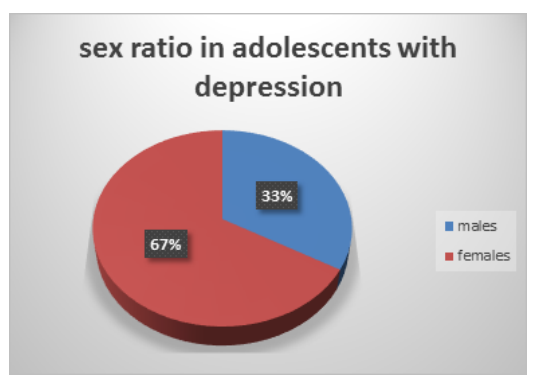

Figure 9:

\section{DISCUSSIONS:}

In this study, the serum iron is seen to decrease in group consisting of adolescents having depression (cases) when compared to the group of normal healthy adolescents (controls). The mean values +/- SD of serum iron of adolescent with depression is $62+/-9.6$ with a coefficient variance of 15.38 . It is highly significant $\mathrm{P}<0.001$ and $t$ value is 14.42 . As iron is needed for production of dopamine and lack or decrease of dopamine can lead to depression, anxiety etc. More over adolescent depression seems more in females as they are more tend to have iron deficiency anemia. Menstrual blood loss may be a cause for the decrease beside the diet This is seen on the rise in all age groups with a recent survey of teenagers in the united states revealing that $30 \%$ of girls and $14 \%$ of boys experience depression at some point during their teenage years [16] In the study of Kolahi et al. prevalence of anemia in women living in the north west of Tabriz was reported $9.7 \%$ and $75.3 \%$ of anemic patients had iron deficiency anemia [17]. In this present study also female percentage of adolescent depression cases is found to be more ie $(66.22 \%)$ when compared to males $(33.78 \%)$. This is shown in figure 9 and table 4 . Prevalence of nutritional deficiency anemia in adolescents is attributed to poor eating habits for instance consumption of junk foods skipping healthy meals on time, less fruit intake, growing utilization of fizzy drinks. [18] Substantial development of brain occur during adolescence and it is vulnerable to the effect of diet which shows iron deficiency and is also associated with cognitive alterations in adolescents, a study by Brunner AB et al in 1996 [19]. Relationship of iron and brain function, cognition and behavior (including emotional behavior) has been the subject of study of interest for researchers over the past decade [14] Here in the study, the mean values +/- SD of serum ferritin in group containing depressed adolescent is $66.57+/-5.07$ with coefficient variance of 36.34 and this is decreased compared to the group of normal healthy individuals. It is also highly significant $\mathrm{P}<0.001$. This gives an additional link with iron deficiency as it is the protein which stores iron. Changes in iron metabolism has been suggested as potential pathological markers in patients with depression. Ferritin as an intracellular iron storage plays an important role and this issue has become the subject of extensive investigation .[20] The fact that mean ferritin level was lower in depressed students than in healthy ones can indicate the possible role of iron in brain function and establishment of depressive mood.[21] Iron plays an important role in the oxygenation of brain parenchyma and the synthesis of many neurotransmitters and enzymes of the nervous system.[14]As a negative effect on depression, a sufficient amount of iron is particularly needed for the synthesis of dopamine, a neurotransmitter that plays a significant role in mood disorders [22] Kaplan H I et al in 2003 in their study found depressed levels of blood dopamine in depression.[23] There is well documented evidence in the literature that iron deficiency anemia (IDA) has a significant influence on cognitive development, intelligence and developmental delay.[24,25] Some clinical studies supposed that brain iron deficiency involved in pathophysiology of attention deficient hyperactivity disorder.[26] and ferritin level was related to behavioral symptoms of ADHD patients.[27]. Using a longitudinal cohort study of 191 participants to evaluate the association between IDA in infancy and affective and developmental outcome in adolescents, Lazoff et al revealed that those with IDA in infancy exhibited more anxiety, depression, social attentional problems in later life [25] Vahda Shariatpanaahi et al studied 192 female medical students and found mean ferritin levels of students with depression was significantly lower than that of healthy students. [21]. Yi S et al in a study of 312 men found that those with lower serum ferritin concentration levels had a higher prevalence of depression symptoms [28]. These two studies supported our findings in relation to serum ferritin where we found it to be lower in case of depressed adolescents. Bansal V et al studied in a group of school children and found $15.2 \%$ of adolescents had evidence of distress and $18.4 \%$ were found to be depressed [29]. The study of Onder et al shows that $15 \%$ of people with depression were anemic [30] This supports our study where serum iron level was significantly found to be low in adolescents with depression

\section{CONCLUSION:}

From this study it was found that the nutritional status should be investigated when dealing with an adolescent depression case as low serum iron and low serum ferritin has an active role in causation of mental illness like depression

\section{REFERENCES:}

Murray CJL, Lopaz AD; The global burden of disease - World health organization 1996 Murray CJL, Lopaz AD; The global burden of disease - World health organization 1996 Ladek M, et al. Global burden of diseases, injuries and risk factors for young people's health during 1990-2013. Lancet, 2016;387:2383-401 
2. Thapar A, Collishan S, Potter R, Thapar A K, Managing and preventing depression in adults. BMJ. 2010; 340:C209

3. Lavinsohn P M, Pettit JW, Joiner T E, Seeley J R. The symptomatic expression of major depressive disorder in adolescents and young adults, J. Abnorm Psychol. 2003;112:244-52

4. American Psychiatric association. Diagnostic and statistical manua lof mental American Psychiatric association. Diagnostic and statistical manua lof mental
disorders-4, Washington D C:American Psychiatric association; 1994

5. Kessler R C,Avenovoli S, Reis Merikangas K, Mood disorders in children and adolescents: an epidimologic prospective. Biol Psychology. 2001;49:1002-14

6. Green H, Mcginnity A, Meltzer H, Ford T, goodman R, Mental health of children and young people in great Britain. 2004.Bagsingstole, U K: Palgrave Macmillan :2005

7. American Psychiatric A ; Diagnostic and statistical manual of mental disorder 4thed, Washington DC:2000

8. Yourdine MB, Ben-Shanchen D, Ashkenazi R, Yehuda S; Brain, iron and dopamine receptor function, AdvBiochem Psycho-pharmacol, 1983:37309-321

9. Conner J R,Menzies S L. Relationship of iron to oligodendrocytes and myelination. Glia 1996: 17(2); 83-93.Doi

10. Unger EL, Branco LE, Jones BC, Allen RP, Early CJ; Low Brain iron effects and reversibility on striated dopamine dynamics: Exp neural ; 2014:261462-468

11. Kaplan HI, Kaplan \& Sadock's synopsis of Psychiatry. Philadelphia, PA: Lippincott William's \& Wilkins;2003..Doi 10.1345/aph.IP356

12. Theil EC (2012). "Ferritin protein nanocages - the story"

13. Chawla R, EL Metwally TH, Sahu S.Mineral Metabolism, Textbook of Medical Biochemistry 2nd edition: page 193-197

14. Beard J D, Conners J R, Jones B C.(1993).Iron in the brain. Nutri Rev 51,157-170

15. Agarwal,BL."'Tests of Significance" Basic statistics; 2nd edition: Pg 200-232

16. Breslau J, gilman SE, Stein BD, Ruder T, Gmelin T, Miller E. Sex differences in recent first onset depression in an epidemiological sample of adolescents. Transl Psychiatry 2017;7(5)

17. Noorazar SG.et al .Relationshipnbetween severity of depression symptoms and iron deficiency anemia in women with major depressive disorder, J Anal Clin Med, 2015,3(4):219-24

18. Hanafi M I, Abdallah A R and Zaky A. Study of haemoglobin level and body mass index among preparatory year female students at TaibahUniversity,Kingdom of Saudi Arabia. Journal of Taibah university medical sciences. 2013; 8(30):160-166

19. Bruner AB, Joff A, Duggan AK, Casella JF, Brandt J,.Randomised study of cognitive effects of iron supplementation in nonanemic iron deficient girls. Lancet:1996;348:992-996

20. Orine $\mathrm{k}$, Watanobe K. Molecular, physiological and clinical aspects of the iron storage protein ferritin. Vet J:2008;178(2):191-201

21. Shariatpanaahi M Vahdat et al . the relationship between depression and serum ferritin level. Europian J of Clin Nutri(2007);61:532-535

22. Paul I, Tumer R E, Ross D(2002). Update Nutrition, 8thedn.John Pow Company:USA

23. Kaplan H I, Sadox B J, Grebb J A(2003) synopsis of Psychiatry, 9theditionWilliams and Wilkins:USA

24. Grantham-Mc Gregor S, Ami C.A view of studies on the effect of iron deficiency on cognitive development in children J.Nutri 2001; 131(25-2):649S-666S

25. Lezoff B, Jimerez f, Wolf AW Long term developmental outcome of infants with iron deficiency. N Eng J. Med. 1991;325(10):687-694

26. Cortese $\mathrm{S}$ et al.Brain iron levels in attention deficit/hyperactivity disorder: A pilot MRI study world J. Biol Psychiatry.2012;13(3):223-231 Oner O et al . Relation of ferritin levels with symptoms, cognitive performance in

27. children with attention deficient hyperactivity disorder. Pedia Int.2008;50(1):40-44

28. Yi S, Nanri A, Paudal Tand. Association between serum ferritin concentration and depressive symptoms in Japanese municipal employees. Psychiatry Res. 2011;189(3):368-372

29. Bansal $\mathrm{V}$ et al. Study of prevalence of depression in adolescent students of a public school. Industrial Psychiatry Journal. 2009; Jan-Jun;18(1):43-46

30. Onder G, et al. Anemia is associated with depression in older adults: results from In CHIANTI study. J Gerontol A Biol Sci 2005;60(9)1168-72 